\title{
FE Simulation Modelling and Exergy Analysis of Conventional Forging Deformation Behaviour of Material Processing
}

\author{
Santosh Sanodiya ${ }^{1}$, Dr. Manvijay Singh $^{2}$, Dr. Keshavendra Choudhary ${ }^{3}$ \\ ${ }^{I}$ Research Scholar, Department of Mechanical Engg, Dr. K.N. Modi University, Newai, Rajasthan \\ ${ }^{2}$ Prof. \& Head, Department of Mechanical Engg, Dr. K.N. Modi University, Newai, Rajasthan \\ ${ }^{3}$ Principal, School of Research and Technology, People's University, Bhopal, M.P.
}

\begin{abstract}
The present paper examines the deformation behaviour of geometrical specimens of an aluminium alloy undergoing axial compression in a Universal Testing Machine under dry condition. It is observed that researchers have made attempts to investigate alternate specimens for friction calibration. It is found that ring compression test is recommended as the standard test for determination of coefficient of friction, because it gives reliable results. The effect of weight percentage of silicon carbide on microstructure, hardness and upsetting load is studied. The friction factor at die metal interface is evaluated by ring compression tests and its effect on non-uniform deformation is investigated. The experimental results are finally compared with those obtained by FEA simulation and modelling. In order to validate the predictability of these specimens, real experiments on them are carried out. Rings of standard dimensional ratio 6:3:1 in the same machine. Friction predictions from both specimen are found to be in close match, proposed alternate specimen offers a powerful tool for friction prediction in the absence of ring specimen. Some aspects of Exergy calculations have been in the past repeatedly used to quantify the quality and quantity of energy used in thermal energy processes. This attempt to drive a exergy utilization and compare for the first time two entirely different manufacturing processes, material processing by a mechanical method of straining of the material and thermal processing during cold forging of the same mass of the material using exergy formulation as metric. The exergy analysis of material processing is determined by performed work and utilized heat transfer using mechanical and thermal processes.
\end{abstract}

Keywords: Forming; Friction; FEA; Calibration Curve; Ring compression; Non-Conventional Specimen; Exergy

\section{INTRODUCTION}

Metal forming processes have been widely used in various industries, including automotive, aerospace, medical, appliance, beverage containers, etc. Metal forming processes involve changing the shape of the work piece by forcing it to flow through a die. Forming can be defined as a process in which desired size and shape is obtained through the plastic deformation of a material. This requires immediate contact between the die (tool) and the work piece. In general, the work piece and the die move relative to each other under pressure or deforming force, which is normal to the die/work piece interface. As a result of this contact, tangential forces are generated at the interface of the die/work piece to resist the relative movement. In order to analyze forming processes, the metal flow, the friction at the die/work piece interface and formability of material have to be described for a given process. For example the coefficient of friction in cold forming is generally of the under of 0.1 , whereas that in hot forming can be as high as 0.6. Production and consumption of goods is increasing more voluminous in manufacturing fields and will be even much faster in the future. What should be done to keep up with the increasing demand and customers wanting better quality products but with less pronounced impact on surroundings and with increased positive impact on society? There is a need to develop and maintain sustainable processes in every field and manufacturing is no different. The ever increasing demands and better quality creates a need to develop and continuously monitor and evaluate the appropriate metrics for assessment for manufacturing processes. One such metric for comparison is attempted to be developed in this thesis by the use of thermodynamics and it is based on the concept of exergy (2005). Exergy is the maximum extractable available energy from a system when it interacts with its surroundings. It carries the same units as work (energy), which is Joule (in SI system of units). However, exergy is not conserved like energy (2005). Every process in manufacturing is founded on the basic principles of conservation and transfer of energy between the involved systems, and thus deals also with transfer, use and destruction of exergy. So, the use of the exergy concept would be plausible as a metric to compare two processes. The concept of 
exergy is derived from the First and Second laws of Thermodynamics and with an emphasis on the Second Law of Thermodynamics. The aim of paper work is to attempt a comparison between two entirely different materials processing activities relevant for manufacturing processes but using the same metric-exergy. The objective of the study is to see whether both can be evaluated and compared using a common metric. There has been not much work done in this particular field of study of systems involving materials processing for manufacturing. To the best of the author's knowledge, there was not a common metric (exergy) that involves both quantity and quality of energy used to compare two entirely different processes. So, the main hypothesis of this work is that a common metric can be used to compare different materials processing with respect to resource (energy) utilization.

\section{ROLE OF COMPUTER SIMULATION IN METAL FORMING}

In metal forming, a piece of material is plastically deformed between tools to obtain the desired product. Before the digital revolution, only few analytical tools were available to judge the manufacturing feasibility. Today, computer based metal forming simulation tools enable the validation of the tool and machine designs for production and an estimate of the final work-piece properties to be expected. The manner in which the material is worked directly determines the final product quality. Kaguchi Shin et al. (2000) demonstrated si-tu measurement is method to read data of reduction in height and change in external diameter of ring specimen by testing machine automatically during compressing. Sofuoglu et al. (2001) developed an alternative method to the ring compression test in order to quantitatively evaluate the coefficient of friction, $\mathrm{m}$; at the die/work piece interface. This technique relates the percentage deformation in height of the specimen to the percentage increase in extruded height of the specimen. Sahin et al. (2005) proposed a new approach to investigate the effect of the surface roughness on the frictional properties for different materials and conditions. Experimental results were placed into ring compression calibration curves for each of the material type and surface conditions. Rudkins et al (1996) performed experimental investigation into friction under hot forming conditions using the ring compression test. Finite-element simulations of the ring compression test were also completed under similar temperatures as in the experiments. The correlation between the experimental measurements and the results of the process modeling is presented in the paper. The analysis had been carried out for different values of friction factor ' $\mathrm{m}$ ' between the die and the specimen and for different values of initial height to diameter (H/D) ratio of the specimen and curves have been plotted for the ratio of spike height to initial height of the billet against the ratio of die displacement to initial height of the billet. Kakkeri et al (2007) analysized the metal forming processes and found that a realistic frictional condition must be specified at the die/work piece interface in order to obtain accurate metal flow. They evaluated the coefficient of friction for Al 2024 and Al 6063. Sofuoglu et al. (2000) investigated the effects of material properties, strain-rate sensitivity, and barreling on the behavior of friction calibration curves. A series of ring compression tests were conducted in order to determine the magnitude of the friction coefficient, $\mathrm{m}$, as well as the corresponding calibration curves for two types of modeling materials, white and black plasticine. The experiments were first conducted using the Physical Modeling Technique (PMT) and then simulated via an elastic-plastic finite element code (ABAQUS). Robinson et al. (2004) studied the ring compression test using physical modelling experiments and finite element (FE) simulation. Using commercially available modelling clay, material stress- strain relationships were obtained from compression tests of solid cylindrical specimens. A series of ring compression tests were carried out to obtain friction coefficients for a number of lubricants including Vaseline, zinc stearate and talcum powder. FE simulations were used to derive the friction calibration curves and to evaluate material deformation, geometric changes and load-displacement results. Further investigation is necessary to determine the effects of material properties, test conditions and use of calibration curves on the ring compression test. Rao K.P. et al (1993) this paper presents a review of the calibration curves developed by various researchers, and discusses their usefulness and limitations for quantitative evaluation of friction and flow stress. The experimental data obtained for some aluminium alloys is used for comparing the validity of the calibration curves. A calibration using a bulge parameter based on the maximum diameter and minimum diameter of the bulge is then developed as a function of the interface friction factor. Hayhurst et al (2004) proposed a new technique to calibrate the model, which utilizes two test piece geometries, namely the solid cylindrical compression test piece and the ring compression test piece. The geometrical changes of all test pieces, carefully measured throughout the tests, for a range of four different friction 
conditions, dry friction, lubricant, lead metal and nylon, have been predicted with good accuracy using the true stress-true strain constitutive models, the two-parameter friction model, and the finite-element analysis procedures. Wang. W et al. (1996) developed a new test to incorporating a smooth increase of wrap angle during deformation, even at high deformation rates, thus replicating typical condition die radii. Bugini A. et al (1993) in this study FEM calibration chart for ring upsetting at room temperature is drawn when dealing with annealed Aluminium specimens of different height. The method allows the evaluation of the friction coefficient affecting the plastic flow when Teflon films are interposed between dies and specimens. Lee Chorng-Der et al. (2001) developed a method to find the friction factor of the die/work piece interface for the forging process without the need for measurement of the shape changes of the work piece. B. Buchner et al. (2008) presented an experimental investigation of friction in hot forging of AA6082, which is a standard forging alloy in automotive engineering, mechanical engineering and in naval architecture, by employing a modified ring-on-disc test.. Rao et al. (2008) used cylindrical $\mathrm{Al}-\mathrm{Cu}$ alloy samples with initial aspect ratios of 1.0 and 1.5 between flat platens in lubricated and dry conditions to predict the metal flow. Micro hardness studies revealed the non-uniform deformation within the specimen. Guerin J.D. et al (1999) in this study The BayWanheim's generalized friction law, developed to model mixed and thin film lubrication cases, is implemented in an industrial finite element software. Both the axisymmetric and 3D formulations are presented. These developments are validated on the ring compression test and numerical, experimental and analytical results are then compared. Joun M.S. et al (2008) compared and investigated the coulomb friction law and the constant shear friction law in detail using a rigid-plastic finite element with emphasis on their application in bulk metal forming. The ring compression test for two different materials was used to evaluate the two friction laws, and then their effect on metal flow lines and forming loads for various friction sensitive metal forming processes were investigated. It was shown that considerable differences exist between the two friction laws, especially in friction-sensitive metal forming processes. To the best of our knowledge no attempt has been made to generate friction calibration curve using centre intrude nonconventional specimens of aluminum material and its validation with standard friction calibration curves. Detailed study on how the friction calibration on specimens behave during deformation and what type of deformation taking place on the FE deformed mesh has not been conducted. The deformation on centre intrudes and its dependency on the characteristics of ring compression test has not been crystallized so for. This could be studied in detailed for in depth understanding through finite

\section{EXERGY ANALYSIS}

Every manufacturing system has inputs, like energy and working materials, and outputs, like finished parts. Additionally, each system creates entropy and waste streams, which are dismissed to the environment. The concept of exergy analysis can be used to characterize and accumulate work, heat and material streams entering and leaving manufacturing systems (2000). An exergy balance can be formulated for every manufacturing system as follows:

$$
B_{\text {in }}+B_{w_{d} \text { in }}+B_{\text {qin }}=B_{\text {out }}+B_{\text {wout }}+B_{\text {q. put }}+B_{\text {lay }}
$$

The exergy of the aggregated materials entering and leaving the system are represented by $B_{\text {inplout }}$.

The components, $B_{W_{i} \text { in } / \text { out }}=W_{\text {in/out }}$ and $B_{Q_{a} \text { in/out }}=\left(1-\frac{T 0}{T}\right) Q_{\text {in/out }}$ show the exergy flows accompanied with work and heat, respectively. Any work required beyond the minimum requirements is lost and expressed by $B_{\text {loss }}$. For this analysis, all exergies $B$ are calculated in respect to the reference state $T_{0}=$ $298.15 \mathrm{~K}$ and $p_{\mathrm{o}}=101.3 \mathrm{kPa}$. The first step in any system analysis is to identify the system boundaries. Depending on the enclosed control volume, results may differ substantially [9]. Here, we investigate this process for two different control volumes.

The method of exergy analysis is well suited for furthering this goal, for it enables the location, type and true magnitude of waste and loss to be determined. Such information can be used to design new systems and to reduce the inefficiency of existing systems. This paper provides a brief survey of both exergy principles and the current literature of exergy analysis with emphasis on areas of application.

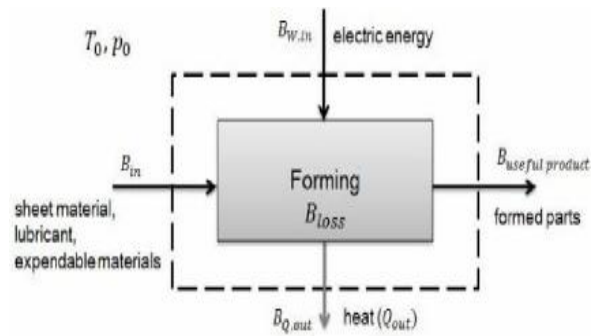

Fig. 3. Control volume forming $\mathrm{m} / \mathrm{c}$ 


\subsection{Concept of Exergy and Its} Applications:

Exergy is a thermodynamic concept and is defined as "Optimal work that can be extracted from a system as it interacts with an environment" (2005). Exergy is additive but not conserved and the different types of exergy $B$ can be represented by the following equation (2001).

$$
B=B k+B_{p}+B_{p} h+B_{c} h
$$

Where $B_{k}$ represents kinetic exergy, $B p$ represents potential exergy, $B p h$ represents physical exergy and $B c h$ represents chemical exergy for better understanding of different types of exergy). There has been a lot of work done in the field of exergy analysis (1999). It is also mainly used in consideration of ecological concepts which can be used to assess the influence on the environment. The basic definition, the concept, the formulation and explanation of exergy use is clearly discussed by Rosen (2005). Before the use of exergy analysis has been developed, the energy analysis has been used with a wide range of economic, environmental and efficiency studies. Brunhes showed the drawbacks of energy assessments only. The loss of exergy which is caused by the irreversibility of the process is directly linked to the entropy change. The relationship that defines this loss is called the Gouy-Stodola's theorem represented by the following equation (1999).

$B=T_{0} \sum(\Delta S)$

This particular equation is extensively used in paper especially for the thermal exergy calculations. This provided the base to correlate the entropy generation and exergy utilization meaningfully. This value is obviously very low; therefore the exergy analysis reveals clearly the possibilities for improvement. The study is done on material, energy and exergy balances of the system as a whole and of its separate elements.. Process design guides transforming of raw materials into the finished products (2000). This study promotes two approaches for process design. One being hierarchic (called in the study) the other approach being mathematical approach. Using the exergy calculations, a new approach for chemical process synthesis has been developed. It shows that this approach may be used to define a more exergy efficient benzene synthesis process (2000).

\section{EXERGY UTILIZATION FOR MATERIALS PROCESSING OF Al ALLOY}

The analysis offers an approach to both theoretical and experimental evaluation of mechanical (elastic and plastic) exergy utilization needed to perform certain mechanical deformation. This exergy amount constitutes a component of the overall exergy utilization within a material's processing during manufacturing. Assume that the material used to manufacture, say the heat exchanger tubes of a compact heat exchanger is initially in the form of a flat plate (without considering elastic/plastic exergy for due to a prior process of metal forming. The cylindrical bar has a diameter $D$, length $l$, and height $h$ as indicated in Fig 4. The cylindrical material is characterized with a stress-strain diagram similar to the one shown.

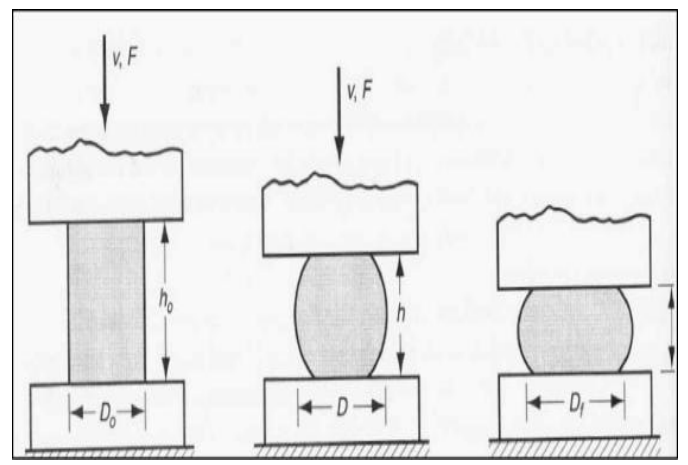

Fig 4 .Initial (a) and final (b) shape of the material before and after metal forming

The conclusion made was that the substitution of useful energy by the value of minimal exergy consumption when studying chemical or metallurgical processes and manufacturing a product makes it possible to apply such universal indices as energy and exergy efficiencies. An exergy analysis is the combination of the first and second laws of thermodynamics. In an exergy analysis, the time rate of heat does not have the same value as the power, and the losses represent the real losses of work. When analysing novel and complex thermal systems, however, such experience needs to be supplemented by more rigorous quantitative analytical tools, and exergy analysis provides those tools. If the system operates at a steady state, steady flow condition, and all the non-reacting gases are arbitrarily assigned as zero thermo mechanical enthalpy, entropy, and exergy under the conditions of ambient pressure and temperature regardless of their chemical composition, then the entropy of mixing different gaseous components can be neglected and the general exergy balance is given as (2002) 


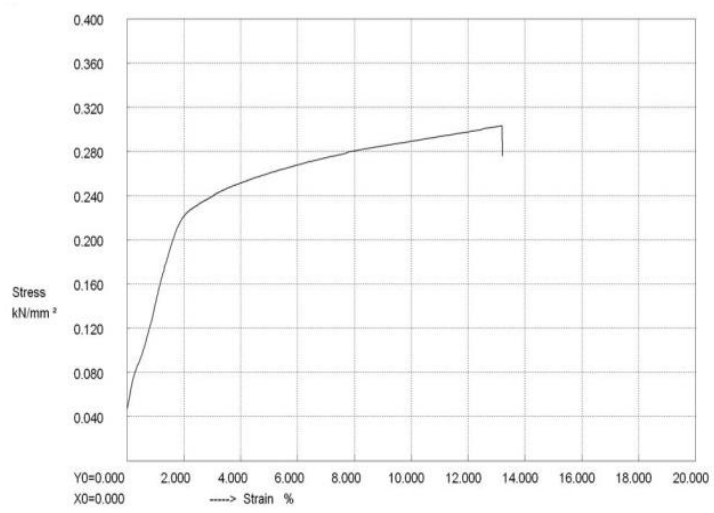

Fig. 5 The Stress- strain curves of center intrude 1

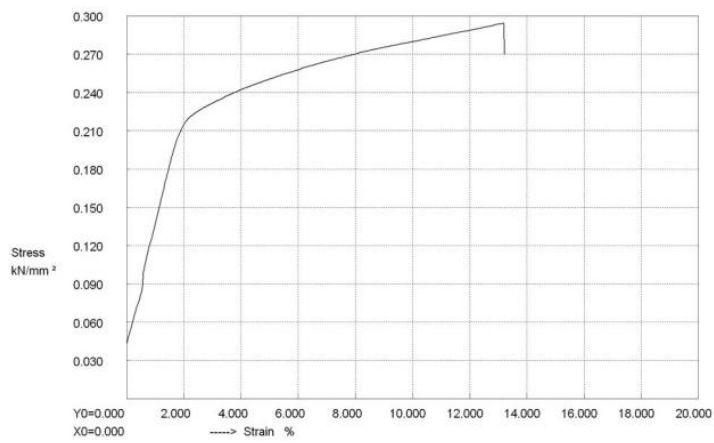

Fig. 6 The Stress- strain curves of center intrude 2

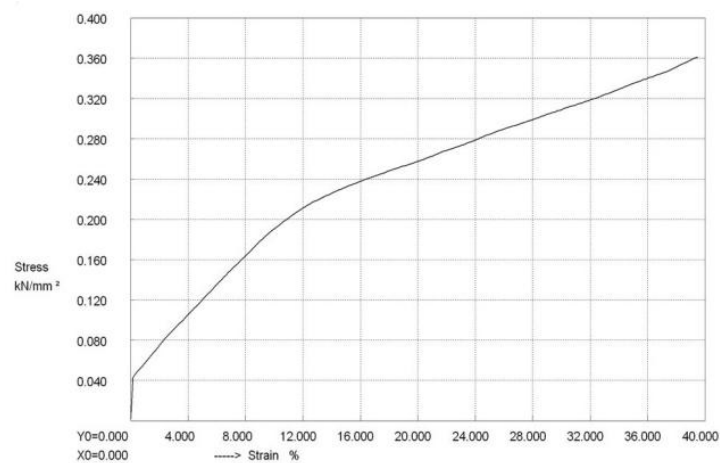

Fig. 7. The stress-strain curves of a ring comp. test

The material undergoes a significant strain during metal forming and there must be significant exergy utilization during this process. The amount of exergy used must be equal to the work done on the material. Hence, in a mechanical process (a process involving a mechanical work only); the exergy use is trivial to determine, if one has all the information needed for determination of the needed work. A need to express this work in terms of exergy, however, is not a semantical issue. The importance of the introduction of exergy is justified by the fact that exergy equivalent of a non-mechanical materials processing would not be possible to determine using the energy balancing only. Such exergy quantity would involve the quality of thermal interactions. In such a manner, a common metric (exergy) for mechanical and nonmechanical processing will be possible to evaluate. The work done in a mechanical process can be obtained by calculating the integral involving the stress-strain dependence (a theoretical amount with no losses). The general shape of the stressstrain curve is presented in Fig 5. The elastic and plastic exergy uses are presented in the Fig 5,6,7. Therefore, calculating the area under the stressstrain curve would give us the work which can be represented as an exergy use involved with material forming (2003).

\section{FEA SIMULATION \& EXPERIMENTS METAL FORMING SETUP}

The methodology of this experimental numerical study on investigation of nonconventional friction specimen incorporates following steps:

To obtain the flow curve, tensile test using a commercial aluminum specimen is carried out. An aluminum specimen of gauge length $80 \mathrm{~mm}$, prepared as per ASTM standard, is tested in a Fine make Universal Testing Machine (UTM). The test and tested specimens are shown in . The summary of the results obtained from the tensile test are as follows:
(a) Ultimate Tensile Strength $=161.57 \mathrm{~N} / \mathrm{mm}^{2}$
(b) Yield strength
(c) Ultimate strain
$=123.13 \mathrm{~N} / \mathrm{mm}^{2}$
$=0.2$
$=0.002$

The engineering stress \& strain are converted into their true counterparts using standard relationships (Kalpakjian and Schmid, 2004). Based on these results, material modeling is carried out using the power law equation (Meyers and Chawla, 1997):

$$
\sigma=\mathrm{k} \varepsilon^{\mathrm{n}}
$$

where $\mathrm{k}$ is the strength coefficient and $\mathrm{n}$ is the hardening exponent. The value of $\mathrm{k}$ and $\mathrm{n}$ obtained from the tensile test results are 225.4 MPa and 0.095 respectively. These data are used in the finite element (FE) simulations. Two centre intrude specimens are proposed for friction study. Geometry of the centre intrude specimen I and II are shown in Fig. 8 \& 9. 


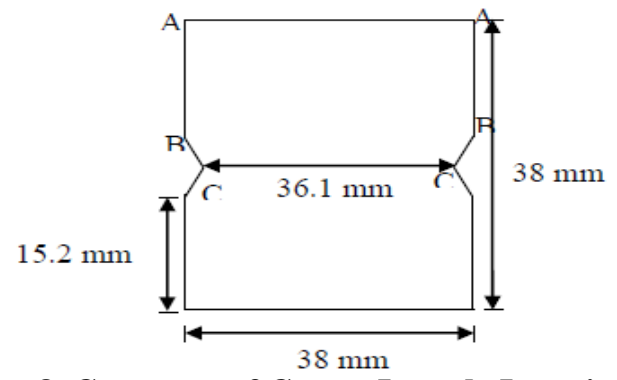

Fig. 8 Geometry of Center Intrude I specimen

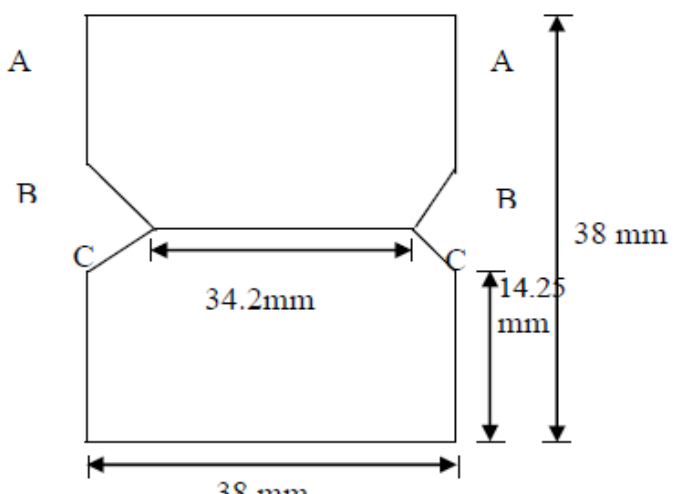

Fig. 9 Geometry of Center Intrude II specimen

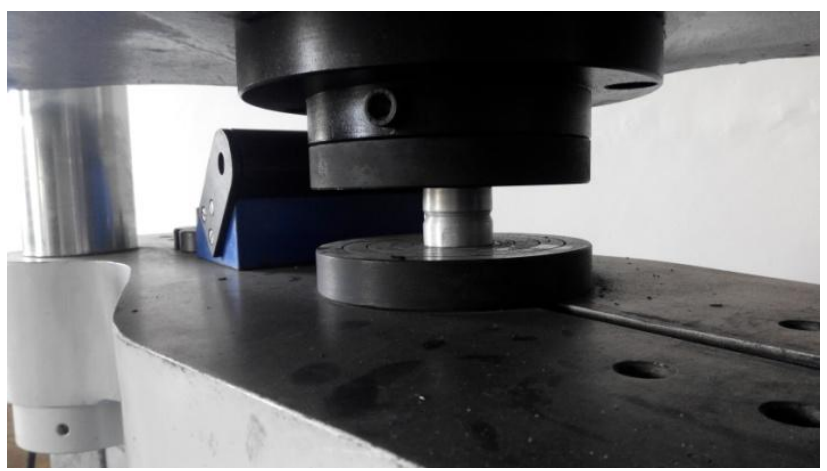

Fig. 10 Prepared Specimen of Center Intrude I

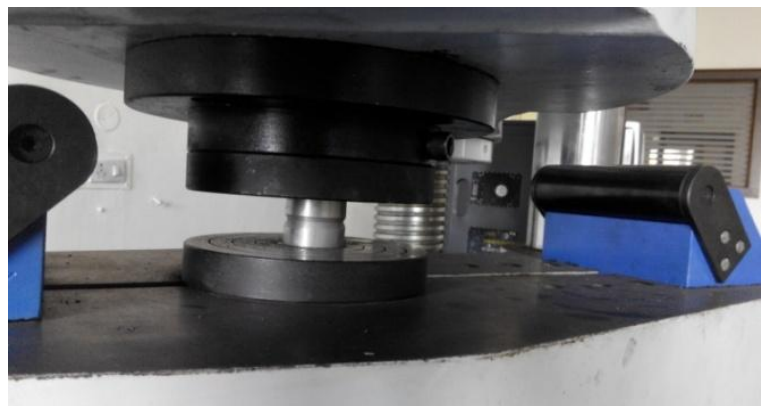

Fig. 11 Deformed specimen of Center Intrude I

\section{PREPARATION OF RING SPECIMENS}

Using the same lathe machine and Aluminum piece two ring specimens are also prepared. The dimensions of the rings are -

(a) Outside Diameter OD $=38 \mathrm{~mm}$ (b) Inside Diameter ID $=19 \mathrm{~mm}$

(c) Height $\mathrm{H} \quad=6.33 \mathrm{~mm}$

A typical photograph of ring preparation by Dieter, $\mathrm{OD}: \mathrm{ID}: \mathrm{H}$ ratio is $6: 3: 1$. Thus prepared ring is shown in Fig. 12.

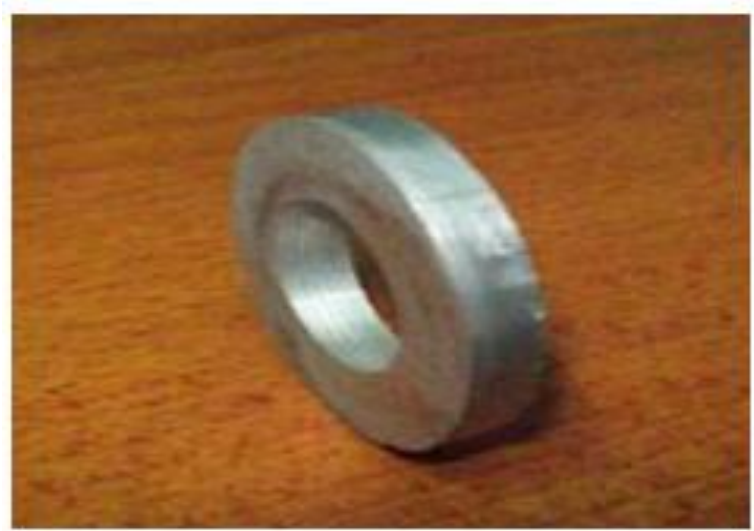

Fig. 12 Prepared ring specimens

\section{Left end}
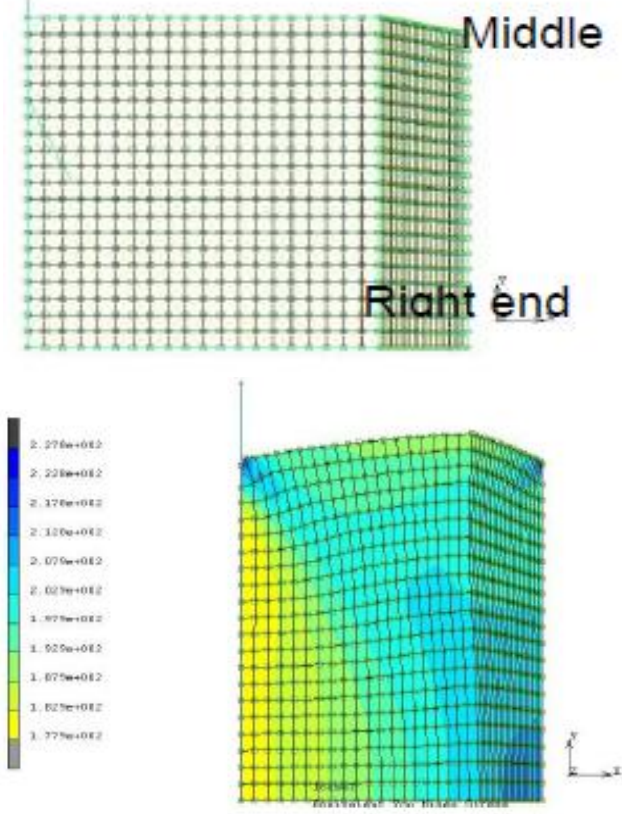

Fig. 13. FEM - model of the Center Inture I (a) before and (b) after compression.

\section{Left end}

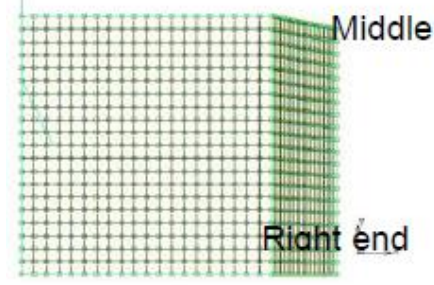



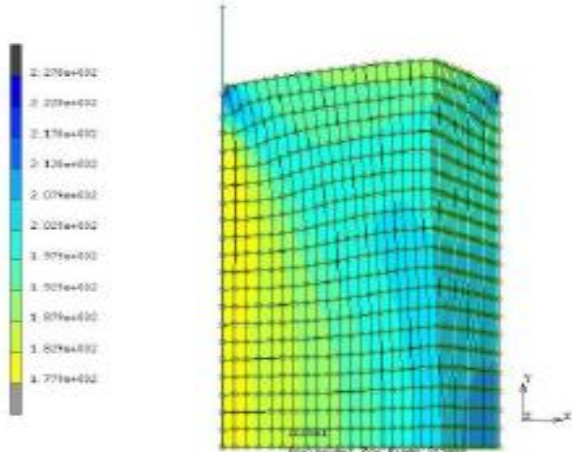

Fig. 14. FEM - model of the Center Inture II (a) before and (b) after compression.

Results of experimental and simulation studies can be described under following heads :-

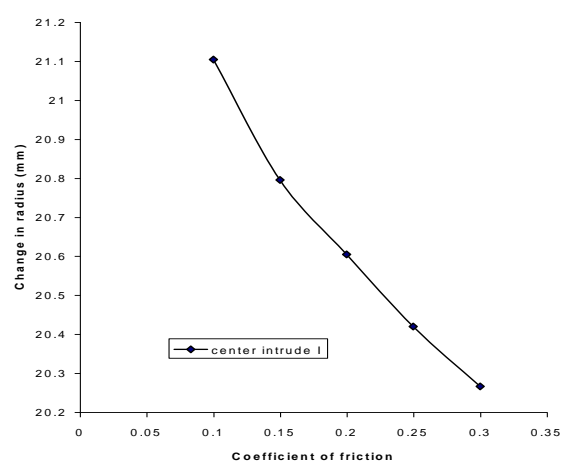

Fig. 15: Friction Calibration Curve Centre Intrude I

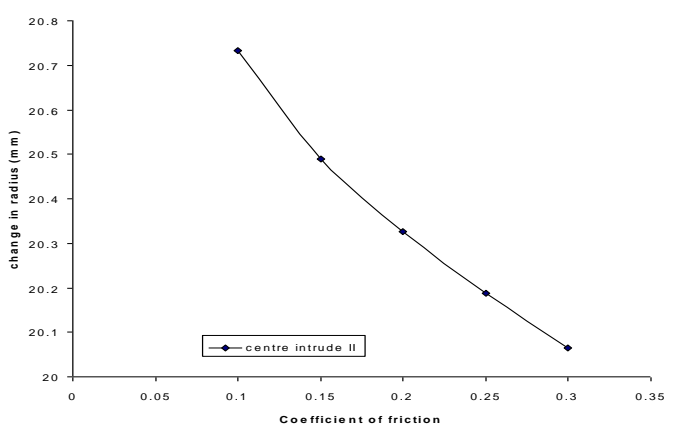

Fig. 16: Friction Calibration Curve Centre Intrude II

Table - 2: Experimental Left End Diameter of Centre intrude I \& II

\begin{tabular}{|c|c|c|c|c|}
\hline \multirow[b]{2}{*}{$\begin{array}{c}\text { S.No } \\
\text {. }\end{array}$} & \multirow[b]{2}{*}{$\begin{array}{l}\text { Specime } \\
\text { n Type }\end{array}$} & \multicolumn{2}{|c|}{ Left end diameter } & \multirow[b]{2}{*}{$\begin{array}{l}\text { Percenta } \\
\text { ge } \\
\text { reduction }\end{array}$} \\
\hline & & $\begin{array}{c}\text { Initial } \\
\text { diamete } \\
\text { r (mm) }\end{array}$ & $\begin{array}{c}\text { Deforme } \\
\text { d } \\
\text { diameter } \\
(\mathrm{mm})\end{array}$ & \\
\hline 1. & $\begin{array}{l}\text { Centre } \\
\text { Intrude I }\end{array}$ & 19.0 & 20.3986 & $6.83 \%$ \\
\hline 2. & $\begin{array}{c}\text { Centre } \\
\text { Intrude } \\
\text { II }\end{array}$ & 19.0 & 20.1689 & $5.78 \%$ \\
\hline
\end{tabular}

It can be observed that friction calibration curves predict quite accurate results as compared to the ring compression test. Hence such alternate specimens may play important role in friction determination in absence of ring specimens. The results obtained for the exergy utilization per unit area for $\mathrm{Al}$ alloy based either on analytical prediction or experimental work indicates a small variation. Therefore, it is concluded that the exergy utilization for Aluminum materials can be performed using 'Ramberg-Osgood' calculations if the empirical values for exponent " $n$ " is calculated. In that case, analytical integration can be performed without a need for experimental data handling. The average value of exergy utilization for mechanical process per unit area obtained from the theory using Ramberg-Osgood equation is $B_{\mathrm{m}, \mathrm{ph}} / \mathrm{A}_{\text {area }}=$ $4218.03 \mathrm{~kJ} / \mathrm{m}^{2}$. and the value obtained from the experiment is $B_{\mathrm{m}, \mathrm{ph}} / \mathrm{A}_{\text {area }}=4147.35 \mathrm{~kJ} / \mathrm{m}^{2}$. For better accuracy of the calculations, the value obtained from the experiments should be considered for comparison. The main point is to deduce that the total exergy utilization to achieve a strain of the body of 0.6 can be used as a metric for exergy utilization to be compared with corresponding values for other processes. The total exergy utilization for volume is equal to the product of exergy utilization per unit square meter times the area of the work piece (pt). That is equal to $B_{\mathrm{m}, \mathrm{ph}} / \mathrm{A}_{\text {area }}=1338 \mathrm{~J}$ of exergy utilization for a given mechanical deformation of 0.07 strain.

\section{CONCLUSION}

Using the concept of exergy two analyses with different control volumes were carried out aiming to compare conventional forming and their processing exergy in case of small production runs.. In this study a search has been made to find alternative specimens for friction calibration using finite element simulation. Two non-conventional specimens were tried for this purpose. It is observed that these two specimens could undergo consistent deformation with respect to varying friction. Friction calibration curve, for these two eligible specimens are generated using simulation results. Actual experiments on these non-conventional specimens were also carried out. A ring of standard dimension is also tested in the same machine. When compared, both specimen gave very close friction value. These non standard specimens can be used as a substitute to ring compression test for friction determination. Hence, friction prediction becomes quite simple using such specimens, especially in the absence of ring specimens. Using the concept of exergy two analyses with different control volumes were carried out aiming to compare conventional forming and their processing exergy in case of small production runs. The first exergy analysis 
showed that the exergy of the material input dominated the electricity input. Particularly, the exergy of the conventional material contributed a significant fraction to the total exergy input. Consequently, the degree of perfection resulted in relatively high values. The main conclusion is drawn from the analysis that Exergy utilization can be used as a common language (as a metric) to asses entirely different processes. If a material undergoes a series of different operations to attain its final shape, one can calculate the total exergy utilization involved in the whole process. And if there is a second series of operations to attain the same product, a comparison of these two methods can be made using exergy utilization as a metric to asses the better of the two methods. One can also infer that the work done in a mechanical processing of straining can be better efficient than the thermal processing of conventional forging at room temperature for the same exergy utilization.

\section{REFERENCES}

[1]. B. Buchner, A. Weber and B. Buchmayr, Investigation of friction in warm forging of AA6082, International Journal Of Material Forming, VOLUME1, supplement/1 January (2008), 1215-1218.

[2]. Bugini A., Maccarini G., Giardini C., Pacaggnella R. and Levi R., The Evaluation of Flow Stress And Friction in Upsetting of Rings and Cylinders, CIRP Annals-Manufacturing Technolgy, Vol. 42, 1993, Pages 335-338.

[3]. Cecil D M R, Rajadurai A, Friction Measurement in Bulk Forming using Spike Forging Test, Journal of Production Engineering Divisional The Institution of Engineers (India), 86, March (2006)

[4]. Guerin J.D., Bartys H., Dubois A. and Oudin J., Finite element implementation of a generalized friction model: application to an upsetting-sliding test, Finite Elements in Analysis \& Design, Vol. 31, 1999, Pages 193-207.

[5]. Hayhurst D.R, Chan M.W., Determination of friction models for metallic die work piece interfaces, International Journal of Mechanical Sciences, Vol. 47 (2005) 125

[6]. Honerkamp, J. (2002). Statistical physics. Springer. p. 298. . "The maximum fraction of an energy form which (in a reversible process) can be transformed into work is called exergy. The remaining part is called anergy, and this corresponds to the waste heat.

[7]. Joun M.S., H.G. Moon, I.S. Choi, M.C.
Lee and B.Y. Jun, Effects of friction laws on metal forming processes, Tribology International, (2008) Pages 311-319.

[8]. Dincer I, Rosen MA. Thermal Energy storage Systems and Applications, John Wiley \& Sons, Chichester (England); 2002.

[9]. Kaguchi Shin (Hachinohekodai Daigakuin) and Ouchi kiyoyuki (Hachinohe Inst. of Technol., Fac. of Eng.), Measurement of Friction Coefficient in Metal Forging, Bulletin of Hachinohe Institute of Technology, Vol.19; 2000; Pages17-23

[10]. Kakkeri Shrishail, Dinesh P and Kumar Chetan, Determination of friction coefficient by ring compression test for al6063, International Conference on Advanced Materials and Composites (ICAMC-2007), Pages 24-26.

[11]. Kalpakjian, S., and Schmid, S.R., Manufacturing Processes For Engineering, fifth edition, Prentice Hall, 2004.

[12]. Lee C.H. and Altan T., "Calibration Curve for Upset Ring Test with outside diameter, inside diameter, and thickness in a ratio of $6: 3: 1$ Trans. ASME Ser. B: J. Eng. Ind., Vol. 94, 1972, p. 775.

[13]. Lee Chorng-Der, Cheng-I Weng and JeeGong Chang, A prediction of the friction factor for the forging process, Metallurgical and materials transactions B, Volume 32(2001), 137-143

[14]. Meyers M.A., Chawla K.K., Mechanical behaviour of materials, the fundamentals of elastic, Second Edition, (Prentice-Hall, 1999).

[15]. Rao K.P. and Sivaram K., A review of ring-compression testing and applicability of the calibration curves, Journal of Materials Processing Technology, Vol. 37, 1993, Pages 295-318.

[16]. Robinson. T., H. Ou, C.G. Armstrong, Study on ring compression test using physical modeling and FE simulation, Journal of Materials Processing Technology 153-154, (2004) 54-59.

[17]. Rudkins N.T., Hartley. P, Pillinger.I a, Petty. D b, Friction modeling and experimental observations in hot ring compression tests, Journal of Materials Processing Technology, 60 (1996) 349353.

[18]. Sahin Mumin, Cem S. Akata H. Erol, Effect of surface roughness on friction coefficients during upsetting processes for different materials, Materials and Design 28(2), (2007) 633-640. 
[19]. Sivaprasad P V and Davis C H J, An assessment of the interface friction factor using the geometry of upset specimens, Modelling \& Simulation in material science and Engg, Vol 13, (2005), Pages 355-360.

[20]. Sofuoglu H., Gedikli. H., Determination of friction coefficient encountered in large deformation processes, Tribology International, 35 (2002) 27-34

[21]. Sofuoglu Hasan, Assistant Professor, Jahan Rasty, Associate Professor, On the measurement of friction coefficient utilizing the ring compression test, Tribology International, 32(6), (1999), 327-335

[22]. Wang.W, Wagoner.R.H, and Wang X. J., Measurement of Friction under Sheet Forming Conditions, 27A, December (1996), 3971

[23]. G.E. Deiter, "Workability Tests", Metals Handbook Volume 14. Forming and Forging, ASM International, Materials Park, OH, 1988, p379-381.

[24]. G.E. Deiter, Mechanical Metallurgy, Mc Graw-Hill, Inc., Boston, MA. 1986, p539549.

[25]. User' manual, ABAQUS Software Corporation, Santa Ana. California, USA, (2015)

[26]. Szarbut J., Morris, D.R., Steward, R., Exergy Analysis of Thermal, Chemical and Metallurgical Processes, (1988) Hemisphere Publishing Corp., New York, U.S.A., pp330.

[27]. Rosen, M., Exergy, Canadian Consulting Engineer, Don Mills, (2005) Ont: Huge C Mac Lean Publications, Vol.46, pp25-28.

[28]. Brunhes B., La Degradation De L, energie, Flammarion, France, pp410.
[29]. Moran. M.J., Fundamentals of Engineering Thermodynamics, John and Sons, Inc., $3^{\text {rd }}$ edition, pp. 282-291.

[30]. Sorin, M., Hammache, A., Diallo., O., Exergy Based Approach for Process Synthesis, Energy, (2005), Vol. 25., pp. 105-129.

[31]. Bakshi. B., A Thermodynamic Framework for Ecologically Conscious Process Systems Engineering, Computers and Chemical Engineering, Vol. 26, pp. 269282.

[32]. Ugural. A., Fenster. S., Advanced Strength and applied Elasticity, Pearson Education Inc., (2003), pp. 370-413.

[33]. Masini, A., Ayres, L., Ayres, R., The Center for the Management of Environmental Resources, Fontainebleau, France, pp. 2-18.

[34]. Rosen, M., Dincer, I., Exergy methods for assessing and comparing thermal storage systems, International Journal of Energy Research, (2003), Vol.27, pp. 415-430.

[35]. Rosen, M., Dincer, I., A Study of Industrial Process Heating Through Exergy Analysis, (June 2004) International Journal of Energy Research, Vol.28, pp. 917-930.

[36]. Feng, X., Zhong, G., Zhu, P., Zhaolin, Gu., Cumulative Exergy Analysis of Heat Exchanger Production and Heat Exchange Processes, (2004), Energy and Fules, Vol.18, pp- 1194-1198.

[37]. Ayres, R., Ayres, L., Warr, B., Exergy, Power and Work in the US Economy, 1990-1998, (2003)Energy, Science Direct, Vol. 28, pp. 2 19-273.

[38]. Stepanov, V., A Method for Estimating the Energy Efficiency of the Economy, (1995) Energy, Vol.20, pp.577-583. 